\title{
The secretory IgA system of lung secretions in chronic obstructive bronchitis: comparison of sputum with secretions obtained during fibreoptic bronchoscopy
}

\author{
J WIGGINS, SL HILL, RA STOCKLEY
}

From the University Immunodiagnostic Research Laboratory and the General Hospital, Birmingham

ABSTRACT The constituents of the secretory immunoglobulin A system (dimeric IgA, total secretory component and free secretory component) were measured in sputum sol phase, tracheal aspirates, and bronchoalveolar lavage fluids from 15 patients undergoing fibreoptic bronchoscopy. All of the proteins showed a progressive decrease in concentration from sputum to the bronchoalveolar lavage fluids $(2 p<0.001)$. Standardisation of samples by means of protein concentration ratios showed that all secretions were generally similar in respect of their secretory IgA profiles, although major differences remained in some individual patients. The between patient variability of the results was generally reduced by the use of protein concentration ratios, allowing closer comparison between subjects. When the secretion albumin concentration was used as a standard, however, it increased the variability of the sputum sol phase IgA components $(2 p<0.01)$, whereas it decreased the variability of the $\operatorname{IgA}$ components in the bronchoalveolar lavage fluid $(2 \mathrm{p}<0.05)$. The role of albumin as a standard protein for assessing the secretory $\operatorname{IgA}$ system in lung secretions remains uncertain.

The secretory IgA system plays an important part in the protection of epithelial surfaces and lung secretions contain large amounts of IgA in both its monomeric $(7 S)$ and its dimeric $(11 S)$ forms ${ }^{1}$ and also secretory component, which may be either free ${ }^{2}$ or bound to dimeric IgA forming the complete secretory $\operatorname{IgA}$ molecule. Serum deficiency of $\operatorname{IgA}$ is associated with recurrent chest infections ${ }^{3}$ and indirect studies have suggested that "local" IgA deficiency may contribute to morbidity in patients with chronic bronchitis. ${ }^{4}$ More recent studies using direct immunological techniques to measure all the components of the IgA system in sputum have identified patients with local abnormalities in the presence of normal serum IgA concentrations. ${ }^{5}$

Sputum is a mixture of secretions from the nasopharynx and bronchial tree, and because it is readily obtainable from patients with productive cough it is suitable for studying local IgA in large

Address for reprint requests: Dr RA Stockley, General Hospital, Birmingham B4 6NH.

Accepted 3 February 1984 groups of patients. Contamination by saliva and other nasopharyngeal secretions may, however, affect the results, although the effect may be largely dilutional. An alternative approach is to study secretions obtained directly from the lung during fibreoptic bronchoscopy. Although this method overcomes the problems of salivary contamination it is invasive and unsuitable for the routine study of large populations and repeat studies are rarely justifiable. Furthermore, the results from samples obtained by bronchoscopy remain difficult to interpret because of variable dilution of the secretion by anaesthetic fluid used during the procedure and by lavage fluids instilled to obtain more distal secretions from the lung.

Sample dilution is a major problem affecting most studies of the protein content of lung secretions. Conventionally, measurements are standardised on the basis of the concentration of a reference protein such as albumin, ${ }^{6}$ which enters the lung secretions by diffusion from serum. It has been suggested, however, that this method of standardisation is inappropriate for assessment of proteins which are locally produced in the lung and that "internal" standardisation using the local proteins themselves 
might be more appropriate, particularly for studies of the secretory IgA system. ${ }^{5}$

In previous work we have suggested that the protein profiles of sputum and of secretions obtained directly from the lung are similar. ${ }^{7}$ Such information is not, however, available for the components of the secretory IgA system.

The purpose of the present study was to compare the $\operatorname{IgA}$ results from sputum sol phase with those of secretions obtained directly from the bronchial tree during fibreoptic bronchoscopy to determine whether any major differences exist, and also to assess the value of standardisation techniques for the study of the secretory $\operatorname{IgA}$ system.

\section{Methods}

Fifteen patients (two of them women) were studied. Their average age was 66.4 (range 48-77) years and all had chronic cough with sputum production and irreversible airflow obstruction (mean $\mathrm{FEV} / \mathrm{FVC} \%$ 55 (SD 14.2)). The patients were studied at least six weeks after an acute exacerbation of their disease and underwent fibreoptic bronchoscopy to investigate either haemoptysis or unexplained chest radiograph abnormalities.

Fibreoptic bronchoscopy was performed after premedication with intramuscular atropine $0.6 \mathrm{mg}$ and intravenous diazepam 5-15 mg. The bronchoscope was passed transnasally after local anaesthesia with lignocaine and passed through the vocal cords after they had been sprayed with two $2 \mathrm{ml}$ boluses of $4 \%$ lignocaine. Subsequent anaesthesia of the trachea and bronchial tree was achieved with three 2 $\mathrm{ml}$ boluses of $2 \%$ lignocaine solution, applied respectively to the carina, the main bronchus, and the lobe to be lavaged.

\section{SECRETIONS STUDIED}

All three secretions were obtained from seven patients.

Sputum was collected as free from saliva as possible (by education of the patient) over a three hour period from all patients on the morning of bronchoscopy, before premedication. Samples were centrifuged at $50000 \mathrm{~g}$ for 90 minutes to obtain sol phase, which was stored at $-70^{\circ} \mathrm{C}$ until it was analysed.

High secretions were obtained from 10 patients and comprised all secretions aspirated into a trap as the bronchoscope was advanced from the vocal cords to the carina.
Bronchoalveolar lavage fuid In 12 patients bronchoalveolar lavage was carried out in the radiologically normal lung. The bronchoscope was gently wedged into a subsegmental bronchus of either the right middle lobe or the lingula. Aliquots of $20 \mathrm{ml}$ sterile normal saline were instilled and gently aspirated into a trap. The procedure was repeated until $120 \mathrm{ml}$ had been instilled. The volume of bronchoalveolar lavage fluid recovered ranged from $10 \%$ to $40 \%$ of the volume instilled.

Formal cytological analysis of the secretions showed that the macrophage was the predominant cell $(>90 \%)$. Samples containing more than 10 red blood cells per millilitre were excluded from analysis to minimise the effects of serum contamination.

To ensure consistency tracheal suckings and bronchoalveolar lavage fluid samples were also centrifuged at $50000 \mathrm{~g}$ for 90 minutes and stored at $-70^{\circ} \mathrm{C}$ until they were analysed.

\section{PROTEINS STUDIED}

Before analysis the bronchoalveolar lavage fluids were concentrated by a known factor (5-10 fold) by means of an Amicon pressure filtration system with a UM2 filter (molecular weight cut off 2000 daltons). The protein concentrations obtained were then divided by the known concentration factor to obtain the protein concentrations for the unconcentrated lavage fluids.

The concentrations of albumin, $\operatorname{IgA}$, and secretory component (SC), both that bound to the complete secretory IgA molecule and the unbound or free secretory component (FSC), were measured immunologically by radial immunodiffusion, monospecific antisera produced in the Immunodiagnostic Research Laboratory, University of Birmingham, being used. Anti-FSC was produced as described previously. ${ }^{5}$ All the other antisera we used are available commercially (Seward Laboratories). The results were expressed as percentages of an appropriate standard: for albumin and $\operatorname{IgA}$ a standard reference serum was used $(100 \%$ standard $=$ albu$\min 44.4 \mathrm{~g} / \mathrm{l}$ and $\operatorname{IgA} 1.57 \mathrm{~g} / \mathrm{l})$; for SC and FSC a standard human whey quantified with pure FSC (a gift from Dr M Lamm, New York Medical Center, New York) was used ( $100 \%$ standard: $\mathrm{SC}=0.46$ $\mu \mathrm{g} / \mathrm{ml} ;$ FSC $=0.25 \mu \mathrm{g} / \mathrm{ml})$. The between batch coefficient of variation for all these measurements was $\pm 4 \%$.

The immunological proportions of IgA present as monomer $(7 S)$ and dimer (11S) were assessed by thin layer chromatography and crossed immunoelectrophoresis (between batch coefficient of variation $\pm 4.1 \%){ }^{8}$ The amount of $11 \mathrm{~S}$ IgA was thereafter expressed as an immunological equivalent to the 
Table 1 Albumin, total IgA, $11 \mathrm{~S} \operatorname{IgA}$, secretory component (SC), and free secretory component (FSC) concentrations (medians with ranges) for seven patients, expressed as percentages of the appropriate standards in the upper half of the table and as protein ratios in the lower half

\begin{tabular}{|c|c|c|c|}
\hline & Sputum & $H S$ & BAL fluid \\
\hline $\begin{array}{l}\text { Albumin } \\
\text { IgA } \\
11 S \text { IgA } \\
11 S \text { IgA } \\
\text { (\% total IgA) } \\
\text { FSC } \\
\text { SC }\end{array}$ & $\begin{array}{l}0.58 \\
(0.37-1.47) \\
17.28 \\
(3.6-33.0) \\
12.6 \\
(1.35-26.7) \\
72.8 \\
(28.7-85.6) \\
1.31-310) \\
(0.37-3.39) \\
5.99-7.81) \\
(0.89-79\end{array}$ & $\begin{array}{l}0.33 \\
(0.13-0.71) \\
8 \cdot 14 \\
(3.18-12 \cdot 02) \\
0.42 \\
(0.3-7 \cdot 3) \\
13 \cdot 3 \\
(3.3-78.6) \\
0.42 \\
(0.11-1.49) \\
1.08- \\
(0.80-2.13)\end{array}$ & $\begin{array}{l}0.05 \\
(0.01-0.19) \\
0.49 \\
(0.15-18.7) \\
0.48 \\
(0.11-1.55) \\
72.8 \\
(8.3-97.0) \\
0.02 \\
(0.01-0.95) \\
0.08- \\
(0.04-1.66)\end{array}$ \\
\hline $\begin{array}{l}\text { FSC/SC } \\
\text { FSC/11S } \\
\text { FSC/albumin } \\
\mathrm{SC} / 11 S \\
\mathrm{SC} / \text { albumin }\end{array}$ & $\begin{array}{l}0.25 \\
(0.18-0.57) \\
0.11 \\
(0.05-0.46) \\
2.31 \\
(0.64-3.57) \\
0.47 \\
(0.26-2.07) \\
9.59 \\
(1.53-13.3)\end{array}$ & $\begin{array}{l}0.40 \\
(0.14-0.73) \\
0.26 \\
(0.06-3.12) \\
0.85 \\
(0.49-4.52) \\
1.90 \\
(0.14-5.07) \\
4.22 \\
(1.44-6.21)\end{array}$ & $\begin{array}{c}0.26 \\
(0.06-0.59) \\
0.09 \\
(0.01-0.61) \\
1.0 \\
(0.08-5.11) \\
0.35 \\
(0.09-1.07) \\
3.83 \\
(0.46-9.44)\end{array}$ \\
\hline
\end{tabular}

HS — high secretions; BAL_bronchoalveolar lavage.

standard serum.

To compare the relative concentrations of SC and FSC in the three secretions (overcoming any difference due to dilution) they were "standardised" for (divided by) the corresponding SC, $11 S \operatorname{IgA}$, and albumin concentrations where appropriate.

Any difference between the secretions was assessed statistically with Wilcoxon signed rank test for paired data (two tailed). The effect of standardisation of FSC and SC for albumin, $11 S \operatorname{IgA}$, and SC on between patient variability in a single secretion was assessed with a normal test for equality of coefficient of variation-that is,

$$
t=\frac{C V_{1}-C V_{2}}{\sqrt{\frac{C V_{1}}{2 n_{1}}-\frac{C V_{2}}{2 n_{2}}}}
$$

The significance of $t$ was determined from tables $(t>$ $1.96-2 p<0.05 ; t>2.57-2 p<0.01 ; t>3.29-$ $2 p<0.001) . C V_{1}$ and $C_{2}$ are the between subject coefficients of variation before and after standardisation and $n_{1}$ and $n_{2}$ are the sample numbers before and after standardisation $\left(n_{1}=n_{2}\right)$.

Coefficients of variation were calculated from the equation $\mathrm{CV} \%=(\mathrm{SD} \div$ mean $) \times 100$.

\section{Results}

ALL THREE SECRETIONS COMPARED

Protein concentrations and protein ratios for the seven patients from whom data were obtained for all three types of secretion are shown in table 1 . The absolute concentrations of all proteins studied in those seven patients were significantly higher in sputum than HS and significantly greater in high secretions than in bronchoalveolar lavage fluid $(2 p<$ $\mathbf{0 . 0 5}$, all comparisons). Individual FSC and SC measurements are shown in the left hand panels of figure 1 .

After standardisation for either $11 S \operatorname{IgA}, \mathrm{SC}$, or albumin there was no longer a significiant difference between any of the three secretions with respect to the relative concentrations of either SC and FSC (table 1 and fig 1). Standardisation of the FSC results for SC resulted in close comparability of the three secretions. In some individuals, however, considerable differences between the three secretions were noted when both $11 S \operatorname{IgA}$ and albumin were used as "standards" (fig 1).

\section{COMPARISON OF PAIRED SECRETIONS}

The median absolute results and ranges obtained from pairs of specimens of sputum and high secretions and sputum and bronchoalveolar lavage fluid in the same patients are shown in table 2 with protein ratios.

Sputum compared with high secretions (10 pairs of specimens)

The absolute concentrations of albumin, total $\operatorname{IgA}$, $11 S$ IgA, FSC, and SC were significantly higher in sputum than in high secretions $(2 p<0.01$, all comparisons). In both secretions, however, the ranges of individual results were wide and between patient variability was great, particularly for high secretions. In some individuals the differences in protein concentrations between the two secretions were small, while in others they were considerable; this is shown for FSC in the first panel of figure 2.

The proportion of IgA present in dimeric form (ie $11 S \operatorname{IgA}$ ) was significantly higher on average in sputum than in high secretions $(2 p<0.05)$ and individual values are plotted in figure 3 . In some individuals the proportions were similar in the two secretions, but in most the proportion of dimeric $\operatorname{IgA}$ was higher in sputum than in high secretions.

The effect of using protein ratios as a method of standardising is summarised in the lower half of table 2. In general terms, the standardisation abolished differences between sputum and high secretions. Although in some individuals protein ratios appeared widely different between secretions there was no significant difference between the secretions for any ratio when the patients were considered as a whole. The closest comparison between secretions for individual patients was observed for the FSC:SC ratio (data not shown). No ratio, however, resulted 


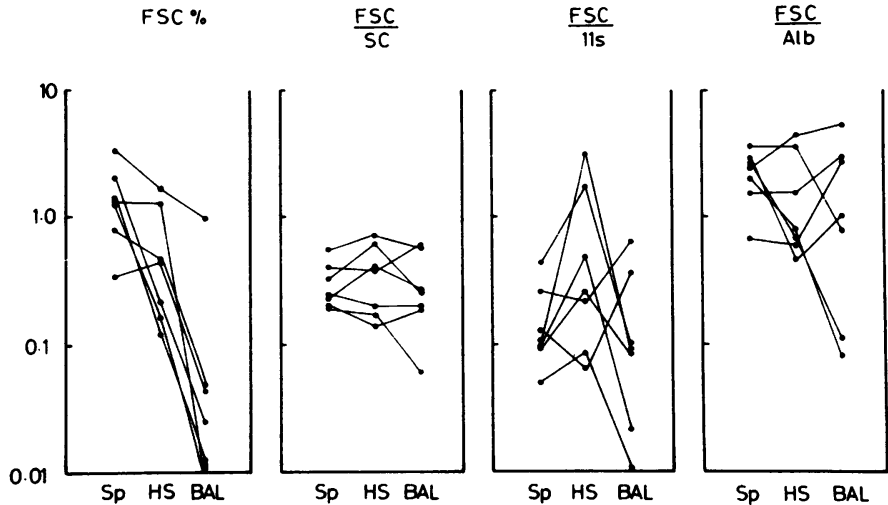

(a)

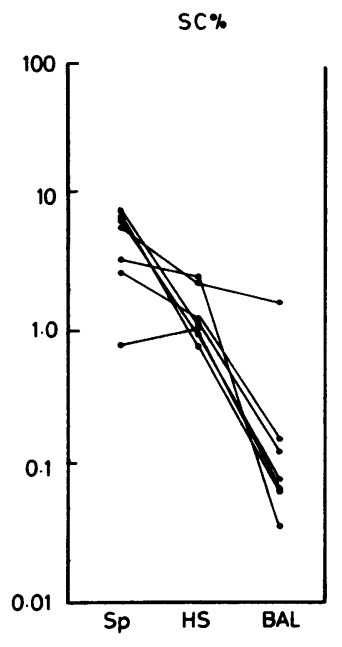

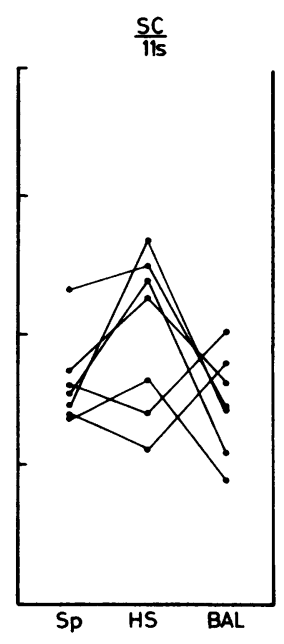

Fig 1 Individual results for free secretory component (FSC) (a) and secretory component (SC) (b), expressed as a percentage of appropriate standards in seven patients from whom all three secretions were collected. Also shown are appropriate protein ratios (standardised results). Each point represents the result from a single sample and the lines join the results from a single patient. Results from sputum (Sp) are shown to the left of each panel; high secretion (HS) results are in the centre and bronchoalveolar lavage fuid $(B A L)$ results are on the right.

(b)

in a significant reduction of the between patient coefficients of variation obtained for the absolute protein concentrations.

Sputum compared with bronchoalveolar lavage fuid (12 pairs of secretions)

In the "understandardised" secretions the absolute concentrations of all proteins studied were significantly higher in sputum than in bronchoalveolar lavage fluid ( $2 p \leqslant 0.01$ ), all comparisons). Ranges of individual values and between patient variabilities were particularly wide in bronchoalveolar lavage fluid; this is shown in the right hand panel of figure 2, which shows the results for FSC.

The median proportion of the total IgA present in dimeric form was not significantly higher for sputum than for bronchoalveolar lavage fluid for the group as a whole $(2 p<0.1>0.05)$. In most patients (eight of 12 ), however, a greater proportion of $11 S$ IgA was found in sputum and in some this constituted a major difference (fig 3 ).

When any of the methods of standardisation were used, there were no longer significant differences in the relative concentrations of FSC and SC between the two secretions compared. Nevertheless, some individual patients still showed major differences, which are clearly outside the limits of accuracy of the method (fig 4). Again, FSC standardised for SC produced the closest similarity of result between the secretions. Between patient variability of both FSC and $\mathrm{SC}$ in sputum was significantly increased by standardisation for albumin $(2 p<0.01)$ and the variability of sputum SC was also significantly increased by standardisation for $11 S \operatorname{IgA}(2 p<0.05)$. In bronchoalveolar lavage fluid, however, standardisation of FSC and SC for albumin significantly reduced variability between patients $(2 p<0.05$ and $2 p<$ 0.01 respectively), although the greatest fall was 
Table 2 Albumin, total IgA, 11S IgA, secretory component (SC), and free secretory component (FSC) concentrations (medians with ranges) for seven patients, expressed as percentages of the appropriate standards in the upper half of the table and standardised ${ }^{*}$ in the lower half

\begin{tabular}{|c|c|c|c|c|c|c|c|c|}
\hline & \multicolumn{2}{|l|}{ Sputum } & \multicolumn{2}{|l|}{$H S$} & \multicolumn{2}{|l|}{ Sputum } & \multicolumn{2}{|l|}{$B A L$} \\
\hline & Median & $\mathrm{CV} \%$ & Median & $C V \%$ & Median & $C V \%$ & Median & $C V \%$ \\
\hline $\begin{array}{l}\text { Albumin } \\
\text { IgA } \\
11 S \text { IgA } \\
11 S \text { IgA (\% total IgA) } \\
\text { FSC } \\
\text { SC }\end{array}$ & $\begin{array}{l}0.62 \\
(0.34-2.17) \\
15.3 \\
(3.6-33.0) \\
12.55 \\
(1.35-26.7) \\
74.2 \\
(28.7-95.4) \\
1.25 \\
(0.37-3.39) \\
3.90 \\
(0.89-7.81)\end{array}$ & $\begin{array}{l}71 \cdot 4 \\
59 \cdot 3 \\
64 \cdot 1 \\
24 \cdot 6 \\
67 \cdot 4 \\
51 \cdot 8\end{array}$ & $\begin{array}{l}0.32 \\
(0.11-0.96) \\
6.98 \\
(1.43-19.4) \\
1.48 \\
(0.3-7.3) \\
24.1 \\
(3.3-84.6) \\
0.20 \\
(0.11-1.49) \\
1.05 \\
(0.37-3.31)\end{array}$ & $\begin{array}{r}73 \cdot 4 \\
64 \cdot 9 \\
108 \cdot 3 \\
78 \cdot 1 \\
108 \cdot 5 \\
64 \cdot 6\end{array}$ & $\begin{array}{l}0.68 \\
(0.16-11 \cdot 12) \\
18 \cdot 19 \\
(3 \cdot 57-46 \cdot 6) \\
13 \cdot 2 \\
(1 \cdot 35-33 \cdot 1) \\
74 \cdot 1 \\
(28 \cdot 7-90.9) \\
1 \cdot 31-3.39) \\
(0.37-37 \\
6 \cdot 17 \\
(0.89-8 \cdot 80)\end{array}$ & $\begin{array}{r}166 \cdot 0 \\
61 \cdot 1 \\
60-7 \\
21 \cdot 8 \\
61 \cdot 8 \\
47 \cdot 5\end{array}$ & $\begin{array}{l}0.05 \\
(0.01-0.19) \\
1.36 \\
(0.15-18.7) \\
0.95 \\
(0.11-2.54) \\
68.4 \\
(8.3-98.0) \\
0.04-0.95) \\
(0.01-0.95) \\
0.12-1.66) \\
(0.04-1.66)\end{array}$ & $\begin{array}{r}83 \cdot 5 \\
160 \cdot 5 \\
78 \cdot 5 \\
46 \cdot 8 \\
223 \cdot 8 \\
156 \cdot 8\end{array}$ \\
\hline $\begin{array}{l}\text { FSC/SC } \\
\text { FSC/11S IgA } \\
\text { FSC/albumin } \\
\text { SC/11S IgA } \\
\text { SC/albumin }\end{array}$ & $\begin{array}{l}0.27 \\
(0.16-0.57) \\
0.11 \\
(0.04-0.46) \\
2.15 \\
(0.18-3.59) \\
0.37 \\
(0.24-2.07) \\
8.47 \\
(1.14-13.3)\end{array}$ & $\begin{array}{r}43 \cdot 1 \\
81 \cdot 7 \\
56 \cdot 7 \\
100.0 \\
6.21\end{array}$ & $\begin{array}{l}0.33 \\
(0.06-0.73) \\
0.20 \\
(0.04-3.12) \\
1.13 \\
(0.21-4.52) \\
1.07 \\
(0.14-5.07) \\
4.05 \\
(1.44-6.21)\end{array}$ & $\begin{array}{r}59.7 \\
161 \cdot 6 \\
91 \cdot 0 \\
104 \cdot 3 \\
37 \cdot 3\end{array}$ & $\begin{array}{l}0.27 \\
(0.14-0.57) \\
0.10 \\
(0.01-0.46) \\
2.13 \\
(0.05-16.4) \\
0.35 \\
(0.24-2.07) \\
7.73 \\
(0.36-47.6)\end{array}$ & $\begin{array}{r}41 \cdot 4 \\
88 \cdot 1 \\
149 \cdot 7 \\
100 \cdot 0 \\
129 \cdot 5\end{array}$ & $\begin{array}{l}0.27 \\
(0.06-0.59) \\
0.09 \\
(0.01-0.61) \\
1.00 \\
(0.08-5.11) \\
0.35 \\
(0.01-1.07) \\
3.95 \\
(0.46-10.0)\end{array}$ & $\begin{array}{r}62 \cdot 2 \\
132 \cdot 7 \\
101 \cdot 0 \\
81 \cdot 2 \\
67 \cdot 2\end{array}$ \\
\hline
\end{tabular}

*Standardised for (that is, divided by) the corresponding SC, $11 S$ IgA, and albumin results.

HS-high secretions; BAL-bronchoalveolar lavage fluid; CV-coefficient of variation.

noted when FSC was standardised for SC, reducing the coefficient of variation from $223.8 \%$ to $62.2 \%$ $(2 \mathrm{p}<0.001)$. On the other hand, although standar-
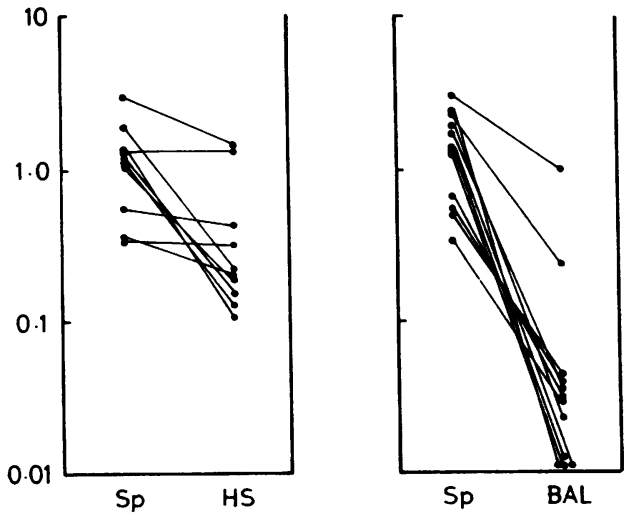

FSC $\%$

Fig 2 Concentration of free secretory component, expressed as a percentage of the appropriate standard, for sputum (Sp) and high lung secretions (HS), and sputum and bronchoalveolar lavage fuid (BAL). Each point represents the results from one sample and lines join results for the same patient. disation of SC and FSC for $11 S$ IgA also appeared to reduce variability (table 2 ), this trend failed to reach significance.
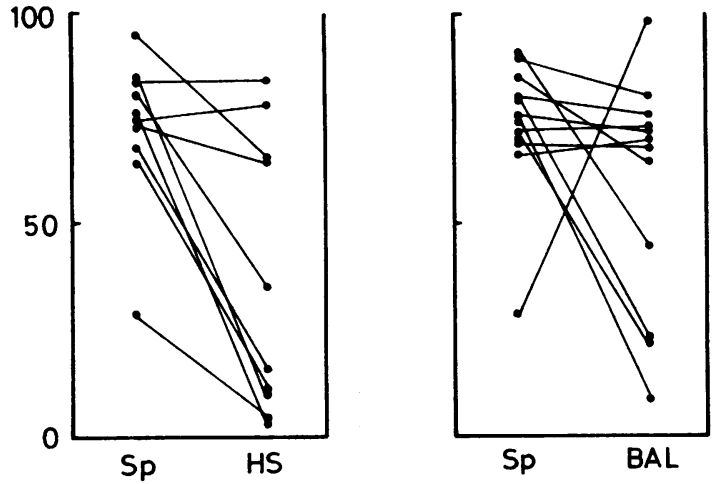

$\operatorname{Ig} A(\%$ dimer $)$

Fig 3 Proportion of $\mathrm{IgA}$ present in its dimeric form shown for sputum (Sp), high secretions (HS), and bronchoalveolar lavage fuid $(B A L)$. Each point is the result for one sample and lines join the results for each patient. 

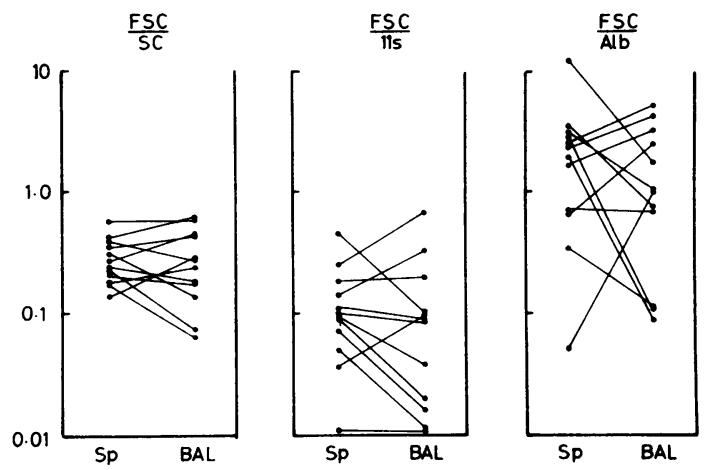

Fig 4 Effect of standardising free secretory component (FSC) for total secretory component, dimeric $\operatorname{Ig} A$, and albumin, shown for sputum and bronchoalveolar lavage fuid in 12 patients. Each point represents the value for a single patient; the results for sputum are on the left of each pair.

\section{Discussion}

The absolute concentrations of albumin, $\operatorname{IgA}$, and the individual components of the secretory IgA system were higher in sputum than either high secretions or bronchoalveolar lavage fluid (fig 1 and 2). These three secretions are subjected to variable and progressively increasing dilutional factors during their collection. Sputum is contaminated with saliva and high secretions with variable amounts of the lignocaine used to anaesthetise the vocal cords, and bronchoalveolar lavage fluids are greatly diluted by the saline used for distal lavage of the lung. Since all the proteins studied were affected in a similar way (that is, a progressive fall in concentration as sampling progressed distally), the differences in absolute protein concentrations between these recovered secretions are likely to be largely due to dilution, as has been suggested for other proteins studied previously.?

To overcome variable dilution and permit comparison of both different individuals and different secretions from an individual, the use of protein ratios as a means of secretion "standardisation" is considered necessary. Albumin has been conventionally used for studies of the proteins of both sputum $^{9}$ and bronchoalveolar lavage fluid, ${ }^{6}$ since this protein is thought to enter lung secretions by simple diffusion. In studies of sputum sol phase, however, we have previously suggested that while this technique is useful for the study of proteins such as $\alpha_{1}$ antitrypsin, which is the same size as albumin and also behaves in a similar way entering secretions from serum by simple diffusion, it may be a less suitable "standard" for proteins such as secretory
IgA, which are locally produced within the lung. ${ }^{10}$ An alternative method of standardisation using the components of the secretory IgA system has been suggested as more appropriate. ${ }^{5}$

In the present studies the sputum results for free secretory component and secretory component standardised for any other protein were similar to the results in both high secretions and bronchoalveolar lavage fluid. The closest comparison was found for the FSC/SC ratio, suggesting a consistent relationship between the total secretory component and the free form for all three secretions.

Differences did emerge, however, when the effect of the standardisation techniques on the between patient variability of paired samples from the same individuals was studied. The sputum and high secretion data were similar but differences were found when sputum was compared with bronchoalveolar lavage fluid. Firstly, standardisation of free secretory component for secretory component (FSC/SC ratio) in bronchoalveolar lavage fluid significantly reduced the between subject variability from $223.8 \%$ to $62.2 \%$, suggesting a benefit from using this ratio in comparison of secretions between subjects where variable degrees of dilution caused by lavage fluid had occurred. Secondly, standardising for albumin (FSC/Alb and SC/Alb) had the opposite effect in the two secretions. Variability was increased in sputum but decreased in bronchoalveolar lavage fluid when these ratios were used (table 2). The reasons for this difference, which suggests that albumin might be a poor standardising protein for sputum but suitable for bronchoalveolar lavage fiuid, are not clear. Possibly the difference is related to the fact that sputum may be diluted with saliva rather than lavage fluid and saliva may not act in a simple dilutional manner in secretions which are expectorated. Alternatively, the difference may be due to the fact that, between patients, secretory IgA (synthesised locally) and albumin (diffusing from serum) in different lung secretions are subject to independent factors that affect their concentrations (such as lung inflammation, serum albumin concentration, and protein metabolism and catabolism). In this respect the observed differences in the proportion of $\operatorname{IgA}$ present in dimeric form in the secretions of some individual patients may well be relevant. Alternatively, we could argue that, although albumin may be a poor internal standard for the secretory IgA system, the dilutional effect of bronchoalveolar lavage fluids may be so great that the overall effect of standardising for albumin may reduce variability, even if this technique is inappropriate for the undiluted secretion. These possibilities will require other carefully designed studies for clarification. The data presented here provide further evidence that "stan- 
dardising" the components of the secretory IgA system for a totally independent protein can increase the variability of the results between subjects in some secretions rather than reduce it.

It is of interest that the "standardised" results from sputum and high lung secretions (obtained at bronchoscopy) were generally similar, since the former is likely to be contaminated by saliva and the latter by local anaesthetic fluid. The effect of this protein free fluid is likely to result in dilution of all secretion proteins to a similar extent. Saliva on the other hand has a much lower ratio of albumin to IgA than sputum has, even though the concentrations of both proteins are reduced, " and thus contamination by saliva would affect the sputum concentrations of the two proteins differently. Perhaps the general similarity of the standardised results for sputum and for high secretions in the patients was a result of educating them to collect relatively saliva free sputum samples.

Nevertheless, some individual differences were noted that could not be explained by the error of the immunological techniques. The most striking differences were in the proportion of $\operatorname{IgA}$ present in its dimeric form (fig 3). Sputum samples from some patients showed that $11 S \operatorname{IgA}$ represented a greater proportion of the total $\operatorname{IgA}$ than the corresponding high secretions or bronchoalveolar lavage fluid. In studies of normal subjects the lung secretions have been found to contain predominantly dimeric (11S) IgA. ${ }^{2}$ In our previous studies, however, ${ }^{1}$ varying degrees of $\mathrm{IgA}$ monomer (7S) have been found in sputum from patients with bronchitis, and Lafitte $e t$ al found a similar difference between lavage samples from patients with bronchitis and from normal subjects. ${ }^{12}$ This may well reflect the increased diffusion of serum (7S) IgA into the secretion of patients with bronchitis contaminating the secretory (11S) IgA. Furthermore, saliva contains almost exclusively dimeric $\operatorname{IgA} .^{13}$ Thus in an individual the between secretion differences in the proportion of IgA present as a dimer which we have observed could possibly reflect individual variations in the contribution of secretory $\operatorname{IgA}$ from saliva and lung secretions, as well as serum derived monomeric IgA from proximal and distal parts of the lungs.

In conclusion, the concentrations of the components of the secretory IgA system were lower in samples obtained directly from the lung than in sputum and this probably reflects dilution of secretions. The secretory IgA protein profiles were generally similar in all secretions studied, though comparison with albumin tended to increase the between patient variability for the sputum results and albumin therefore may not be a useful standard for this secretion. Some individual differences between secretions were observed, though the significance of these findings remains unclear.

We would like to thank Mrs P Jackson for typing the manuscript and the West Midlands Regional Health Authority and Endowment Fund for financial support. JW was a Sheldon clinical research fellow.

\section{References}

' Stockley RA, Afford SC, Burnett D. Assessment of 7S and $11 S$ immunoglobulin $A$ in sputum. Am Rev Respir Dis 1980;122:959-64.

${ }^{2}$ Merrill WW, Goodenberger D, Strober W, Matthay RA, Naegel GP, Reynolds HY. Free secretory component and other proteins in human lung lavage. Am Rev Respir Dis 1980;122:156-61.

${ }^{3}$ Amman AJ, Hong R. Selective IgA deficiency: presentation of 30 cases and a review of the literature. Medicine (Baltimore) 1971;50:223-36.

4 Soutar CA. Distribution of plasma cells and other cells containing immunoglobulin in the respiratory tract in chronic bronchitis. Thorax 1977;32:387-96.

s Stockley RA, Burnett D, Afford SC. The immunological measurement of "free" secretory piece and its relationship to local IgA production. Clin Exp Immunol 1981;45:124-30.

- Reynolds HY, Newball HH. Analysis of proteins and respiratory cells from human lungs by bronchial lavage. J Lab Clin Med 1974;84:559-79.

7 Wiggins J, Hill SL, Stockley RA. Lung secretion sol phase proteins: comparison of sputum results with secretions obtained by direct sampling. Thorax 1983;38:102-7.

${ }^{8}$ Stockley RA, Afford SC, Burnett D. A method for study of local IgA production using radial immunodiffusion and thin layer chromatography. J Immunol Methods 1980;38:151-9.

${ }^{9}$ Stockley RA, Mistry M, Bradwell AR, Burnett D. A study of plasma proteins in the sol phase of sputum from patients with chronic bronchitis. Thorax 1979;34:777-82.

${ }^{10}$ Wiggins J, Stockley RA. Variability in sputum sol phase proteins in chronic obstructive bronchitis: the value of using albumin for standardisation. Am Rev Respir Dis $1983 ; 128: 60-4$.

"Mistry M. MSc thesis, University of Birmingham, 1978.

12 Lafitte JJ, Laine A, Hayem A, Petitprey D, Roussel P, Degand P. Les sécrétions bronchiques: étude biochimique. Aspects physio-pathologues. Eur J Respir Dis 1980;61, suppl 111:25-8.

${ }^{13}$ Brandtzaeg P, Fjellanger I, Gjeruldsen ST. Human secretory immunoglobulins. 1. Salivary secretions from individuals with normal or low levels of serum immunoglobulins. Scand J Haem 1970; suppl 12:183: 